Research Paper

\title{
Correlation of ALDHI and Notch3 Expression: Clinical implication in Ovarian Carcinomas
}

\author{
Mi Joung Kim*, A-Ram Kim²*, Ju-Yeon Jeong 1, Kwang-il Kim¹,3, Tae-Heon Kim¹,3, Chan Lee5, Kwanghoe \\ Chung, ${ }^{4}$ Young-Hyeh $\mathrm{Ko}^{6}$, and Hee-Jung An ${ }^{1,3 凶}$ \\ 1. Institute for Clinical Research, College of Medicine, CHA University, Yatap-dong, Seongnam Si Bundang-gu, Gyeonggi-Do 463-712, Republic of Korea; \\ 2. Department of Biomedical Science, College of Life Science, College of Medicine, CHA University, Yatap-dong, Seongnam Si Bundang-gu, Gyeonggi-Do \\ 463-712, Republic of Korea; \\ 3. Department of Pathology, College of Medicine, CHA University, Yatap-dong, Seongnam Si Bundang-gu, Gyeonggi-Do 463-712, Republic of Korea; \\ 4. Department of Biotechnology, College of Medicine, CHA University, Yatap-dong, Seongnam Si Bundang-gu, Gyeonggi-Do 463-712, Republic of Korea; \\ 5. Department of Gynecologic Oncology, College of Medicine, CHA University, Yatap-dong, Seongnam Si Bundang-gu, Gyeonggi-Do 463-712, Republic of \\ Korea; \\ 6. Department of Pathology, Samsung Medical Center, Seoul, Republic of Korea. \\ * These authors equally contributed for first author.
}

$\triangle$ Corresponding author: Hee -Jung An, M.D., Ph.D., Department of Pathology, College of Medicine, CHA University, 351 Yatap-dong, Seongnam Si Bundang-gu, Gyeonggi-Do 463-712, Republic of Korea Tel: 82-31-780-5439 Fax: 82-31-780-5476 E-mail: hjahn@cha.ac.kr

(1) Ivyspring International Publisher. This is an open access article distributed under the terms of the Creative Commons Attribution (CC BY-NC) license (https://creativecommons.org/licenses/by-nc/4.0/). See http://ivyspring.com/terms for full terms and conditions.

Received: 2016.12.28; Accepted: 2017.08.25; Published: 2017.09.20

\begin{abstract}
Purpose: ALDHI is a putative cancer stem cell marker, while the Notch signaling pathway is involved in regulation of cancer stem cell (CSC)s. This study aims to determine the expression of Notch signaling genes in ovarian CSCs, and to assess the clinical impact of expression of ALDHI and Notch signaling genes in ovarian cancers.

Methods: We examined expression of Notch signaling genes in FACS-sorted ALDHI(+) putative ovarian CSCs and expression of ALDHI and Notch signaling genes in 86 ovarian epithelial tumors and various ovarian cancer cell lines by real-time RT-PCR, including Notch receptors (Notch I-4), Notch ligands (Jaggedl and Jagged2), and the downstream molecule, Hes l. Furthermore, we correlated their expression with clinicopathological parameters and patient's survival in ovarian serous carcinoma (OSC)s, the most prevalent type of ovarian cancer.

Results: The higher expression levels of ALDHI and Notch related genes, especially Notch3 were associated with CSCs and with chemoresistant OSCs and paclitaxel-resistant SKpac ovarian cancer cells. Among the Notch signaling genes, high Notch3 expression was significantly associated with all the parameters of poor prognosis, i.e., advanced stage, lymph node and distant metastases, and chemoresistance, whereas other genes were less correlated with these parameters. A combined upregulation of $A L D H I$ and Notch3 was an independent poor prognostic factor in OSCs.

Conclusions: $A L D H I$ correlates with Notch3 expression in ovarian carcinomas. ALDHI and Notch3 overexpression is an independent poor prognostic indicator for worse patient's survival in this subset of OSCs.
\end{abstract}

Key words: ovarian serous carcinoma, ALDH1, Notch3, cancer stem cells, prognostic indicator.

\section{Introduction}

Ovarian cancer is the most lethal of gynecological cancers and is the fifth leading cause of cancer-related death in women [1]. Despite various efforts of multimodality treatment, the mortality rate has not improved owing to relapse and the development of resistance to first-line chemotherapy
[2]. Cancer stem cells (CSCs) are thought to be important in both tumor recurrence and chemoresistance because of their ability to self-renew, modulate and balance the differentiation of tumor cells, and survive in the presence of conventional treatment $[3,4]$. Thus, the identification of CSCs in 
ovarian cancer is critical for the development of a new therapeutic strategy that will overcome chemoresistance, and lead to improvements in the patient's survival rate.

Among the CSC markers, which include aldehyde dehydrogenase isoform 1 (ALDH1), CD133, CD44, and CD117, ALDH1 appears to be the most potent ovarian CSC marker [5, 6]. ALDH1 is a cytosolic aldehyde dehydrogenase that plays a role in cellular detoxification and retinoic acid metabolism [7]. ALDH1 has been studied as a prognostic marker in ovarian carcinoma (OC), with the most reporting that increased $A L D H 1$ expression is correlated with poor prognosis $[8,9]$. Our previous study of ovarian serous carcinoma (OSC) patients also revealed that a high expression of ALDH1 mRNA was associated with chemoresistance and an advanced clinical stage [10]. We also showed that ALDH1 (+) OC cells overexpressed Notch 3 in our previous study. Considering that the Notch signaling pathway is one of the most important pathways involved in regulating CSCs in a variety of human cancers, Notch 3 overexpression in ALDH1 (+) cells indicate Notch signaling is activated in CSCs. In this regard, recent studies as well as our previous study [11] have demonstrated that Notch3 was overexpressed in many OCs and Notch3 overexpression was correlated with a poor prognosis in OSC patients [12, 13]. However, the comprehensive expression pattern of Notch signaling genes in OC, along with their relationship with CSCs, has not yet been described.

To determine the expression pattern of Notch signaling genes in ovarian CSCs, we examined the expression of Notch signaling genes including Notch receptors (Notch1-4), Notch ligands dominant (Jagged1 and Jagged2), and the downstream molecule, Hes1 in ALDH1 (+) OC cells. Moreover, we analyzed the expression of ALDH1 and various Notch signaling molecules in OSCs, the most prevalent OC that accounts for $80 \%$ of epithelial OC and, subsequently, determined the clinical significance of their expression in OSC patients.

\section{Materials and Methods}

\section{Cell lines and cell culture conditions}

The human OC cell line SKOV3 was purchased from the ATCC (Manassas, VA, USA). Paclitaxel (PTX)-resistant cell lines (SKpac) were established from the parent cell line (SKOV3) by continuous exposure to an increasing concentration of PTX: from an $\mathrm{IC}_{50}$ of $10 \%$ to $1000 \%$. SKpac cells were 365.5-fold more resistant to PTX $\left(\mathrm{IC}_{50}=7.8 \mu \mathrm{M}\right)$ than the SKOV3 cells $\left(\mathrm{IC}_{50}=22 \mathrm{nM}\right)$. Human OC cell lines, A2780 and cisplatin-resistant A2780cis were purchased from the European Collection of Cell Cultures (Salisbury, UK). All cell lines were maintained in McCoy's 5A medium (Gibco/Invitrogen, Carlsbad, CA, USA) with 10\% fetal bovine serum (Invitrogen), $100 \mathrm{U} / \mathrm{mL}$ penicillin, and $100 \mu \mathrm{g} / \mathrm{ml}$ streptomycin at $37^{\circ} \mathrm{C}$ in a humidified $5 \% \mathrm{CO}_{2}$ atmosphere.

\section{The primary cell culture}

The fresh tumor tissues of five cases of OSC were mechanically dissected into small pieces and enzymatically digested into single cell suspensions in PBS containing $50 \mathrm{U} / \mathrm{mL}$ collagenase A (Roche, Pleasanton, CA) and incubated at $37^{\circ} \mathrm{C}$ for $30 \mathrm{~min}$. Epithelial cells selected with Ber-EP4-coated magnetic Dynabeads (Life Technologies, Grand Island, NY) and then cultured in Macoy' 5A medium (Gibco) containing $10 \%$ fetal bovine serum, $100 \mathrm{U} / \mathrm{mL}$ penicillin, $100 \mu \mathrm{g} / \mathrm{ml}$ streptomycin, and $20 \mathrm{ng} / \mathrm{mL}$ epidermal growth factor (Life Technologies).

\section{ALDEFLUOR assay and fluorescence-activated cell sorting (FACS)}

ALDH1(+) cells from primarily cultures OC cells were isolated by ALDEFLUOR assay using ALDEFLUOR assay kit (StemCell Technologies, Vancouver, BC, Canada) according to the manufacturers protocol. Cells were suspended in Aldefluor ${ }^{\circledR}$ assay buffer containing ALDH substrate and incubated for $40 \mathrm{~min}$ at $37^{\circ} \mathrm{C}$. Half the cell/substrate mixture of each sample as a negative control, was treated with a specific ALDH1 enzyme inhibitor, diethylaminobenzaldehyde (DEAB). The brightly fluorescent ALDH1-expressing cells were detected in the green fluorescence channel of $\mathrm{BD}$ FACS Aria III (Becton Dickinson, Franklin Lakes, NJ, USA). Stained cells analyzed and sorted by FACS. Dead cells were excluded using propidium iodide $(1 \mu \mathrm{g} / \mathrm{ml})$. FACS sorting was done in triplicate.

\section{Spheroid formation assay}

Cells were plated at the density of 10,000 cells per well in Ultra-Low Attachment Surface culture plates (Corning, Acton, MA) in serum-free DMEM/F12 medium (Invitrogen) with $20 \mathrm{ng} / \mathrm{ml}$ epidermal growth factor (Invitrogen), $10 \mathrm{ng} / \mathrm{ml}$ basic fibroblast growth factor (Sigma-Aldrich, St. Louis, $\mathrm{MO}), 0.4 \%$ bovine serum albumin (Sigma-Aldrich), and $5 \mathrm{mg} / \mathrm{ml}$ insulin (Sigma-Aldrich). Sphere formation with 50-100 cells per sphere was established 12 days after plating the cells.

\section{Tumor samples}

Fresh tissue samples of 86 ovarian epithelial tumors were obtained from patients who had undergone oophorectomies at the CHA Bundang 
Medical Center at the time of surgery. These included 10 benign ( 5 mucinous, 5 serous), 20 borderline (10 mucinous, 10 serous), and 56 malignant epithelial tumors (7 mucinous, 4 endometrioid, 7 clear cell, 38 serous). Six primarily cultures ovarian epithelial cells were used as normal controls. These were derived from the ovaries of patients who underwent hysterectomies for leiomyomas.

The tumors were divided into chemosensitive and chemoresistant groups based on response to chemotherapy after surgery. Based on the NCCNguidelines, intrinsically chemoresistant tumors were definedas those with persistent or recurrent disease within 6 months after the initiation of first-line taxol-platinumbased combination chemotherapy. Chemosensitive tumors were classified as those with a complete response to chemotherapy and a platinum-free interval of $>6$ Months. This study was approved by the Ethical Committee of the CHA Bundang Medical Center, and informed consent was obtained from each patient prior to surgery.

\section{Real-time RT-PCR of ALDHI and Notch signaling genes}

The total RNA was extracted with TRIzol reagent (Invitrogen). The RNA was then converted into cDNA using a superscript III TM First-strand Synthesis System (Invitrogen). Real-time PCR was conducted on a CFX96 ${ }^{\mathrm{TM}}$ real-time PCR system (Bio-Rad Laboratories, Hercules, CA). The default values of the CFX Manager ${ }^{\mathrm{TM}}$ software (version 1.0) were used to determine cycle threshold (CT). Individual PCRs were performed in triplicate, and the expression of ALDH1, Notch1, Notch2, Notch3, Jagged1, Jagged2, and Hes1, was calculated relative to GAPDH via the $2^{-\triangle \Delta C T}$ equation. Results for tumor samples were represented as fold-changes relative to the mean level of expression of 12 normal ovarian surface epithelial cell controls.

\section{Dual immunohistochemical stain}

Immunohistochemistry (IHC) for detection of co-localization of ALDH1 and Notch3 were performed with formalin-fixed paraffin embedded tissue from 10 chemoresistant OSC tumor samples using Polink DS-GM-Hu C Kit polymer (GBI labs, Bothell, WA, USA) according to manufacturer's protocol. Briefly, blocks were cut at five micromiter thick and the sections dried at $62^{\circ} \mathrm{C}$ for $30 \mathrm{~min}$, and then, subjected to antigen retrieval using cell conditioning solution containing Tris/borate/EDTA in a Ventana BenchMark XT Autostainer (Ventana Medical Systems, Tucson, AZ, USA) for $60 \mathrm{~min}$. For double staining, the slides were incubated for $3 \mathrm{~h}$ with anti-ALDH1 (biorbyt, Canbrige, UK) and anti-Notch3 antibody (GeneTex, San Antonio, USA) at a concentration of 1:100. For the anti-ALDH1 antibody, we used HRP-polymer as a secondary antibody and developed using Emerald green (HRP), and then the slides were counterstained with Meyer Hematoxylin. For the anti-Notch3 antibody, the slides were incubated with AP-polymer as the secondary antibody and development was detected with GBI-Permanent Red substrate (AP).

\section{The clinicopathological correlation}

A clinicopathological correlation with gene expression was performed for OSC, which is the most prevalent tumor type in ovarian cancers. Thirty-eight patients with OSC were examined. Clinical data were retrieved from clinical databases and histopathological examination of tumor samples was performed at the Department of Pathology according to criteria of World Health Organization classification. Ages ranged from 33 to 83 years (median age was 46.8 years). The clinical stages of the carcinomas upon initial diagnosis were as follows: low (I, II) in 6 cases $(15.8 \%)$, high (III, IV) in 32 cases $(84.2 \%)$. Lymph node involvement and distant metastasis were detected in $21(55.3 \%)$ and 10 cases $(26.3 \%)$, respectively. The mean follow-up interval was 32 months (range was 9-86 months). Among the 38 OSC patients, 28 remained alive without disease, while 10 died of the cancer (Table 1).

Table 1. Clinicopathological characteristics of ovarian tumors $(n=86)$

\begin{tabular}{|c|c|c|c|c|c|c|c|c|c|c|}
\hline \multirow[t]{2}{*}{ 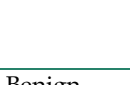 } & \multirow[t]{2}{*}{ Type } & \multirow{2}{*}{$\begin{array}{l}\text { Case } \\
\text { (No.) }\end{array}$} & \multicolumn{2}{|c|}{ Stage } & \multicolumn{2}{|c|}{ Nodal metastasis } & \multicolumn{2}{|c|}{ Distant Metastasis } & \multicolumn{2}{|c|}{ Chemoresponse } \\
\hline & & & I, II & III, IV & $\mathrm{N}$ & $\mathrm{P}$ & $\mathrm{N}$ & $\mathrm{P}$ & $\mathrm{R}$ & $S$ \\
\hline \multirow[t]{2}{*}{ Benign } & Mucinous & 5 & - & - & - & - & - & - & - & - \\
\hline & Serous & 5 & - & - & - & - & - & - & - & - \\
\hline \multirow[t]{2}{*}{ Borderline } & Mucinous & 10 & 10 & 0 & 10 & 0 & 10 & 0 & - & - \\
\hline & Serous & 10 & 10 & 0 & 10 & 0 & 10 & 0 & - & - \\
\hline \multirow{4}{*}{$\begin{array}{l}\text { Malignant } \\
\text { tumor }\end{array}$} & Mucinous & 7 & 5 & 2 & 7 & 0 & 6 & 1 & 1 & 6 \\
\hline & Endometrioid & 4 & 3 & 1 & 3 & 1 & 4 & 0 & 0 & 4 \\
\hline & Clear cell & 7 & 4 & 3 & 4 & 3 & 6 & 1 & 1 & 6 \\
\hline & Serous, HG & 38 & 6 & 32 & 28 & 10 & 17 & 21 & 13 & 25 \\
\hline Total & & 86 & 38 & 38 & 62 & 14 & 53 & 23 & 19 & 37 \\
\hline
\end{tabular}

HG: High grade, P: positive, N: Negative, R: resistant, S: Sensitive 


\section{Statistical analysis}

Comparison of mRNA expression between groups was determined using the Student's t-test. The correlation between the expression of ALDH1 and that of Notch signaling genes was determined using Spearman's correlation analysis. Associations between clinicopathological factors and the expression of genes were determined using the $\chi^{2}$ test or Fisher's exact test. For survival analysis, the Kaplan-Meier method and multivariate Cox regression analyses were performed, and resultant curves were compared via a log-rank test. A p-value < 0.05 was considered statistically significant. Statistical analysis was performed using the SPSS 19.0 statistics software package (Chicago, IL, USA).

\section{Results}

\section{Isolation of ALDHI (+) cells in OSC primary cells}

We isolated ALDH1 $\left(^{+}\right)$cell by ALDEFLUOR assay for recruiting the cancer stem cells in primarily-cultured OSC cells. Cells were labeled with ALDEFLUOR reagent in the presence or absence of the ALDH inhibitor, DEAB. ALDEFLUOR-labeled cells were analyzed by flow cytometry. In the presence of the ALDH-specific inhibitor DEAB, ALDH1 $(+)$ cells were rarely observed $(0.1 \%)$. The absence of DEAB displayed ALDH1 $(+)$ population $(0.9 \sim 6.74 \%)$ in primarily-cultured OSC cells (Fig. 1A).

\section{Expression of $A L D H I$ in spheroid forming cells}

We performed real-time RT-PCR to assess the ALDH1 mRNA expression in primary tumor cells and spheroid forming cells from 5 different OSC tumors. Spheroid forming cell were obtained from the culture system with serum-free medium, in which non-CSCs cannot survive. In this culture condition, cells were grown as non-adherent sphere clusters, the spheroid formation with 50-100 cells per sphere was observed on day 12. The spheroid-forming cells were harvested, and expression of $A L D H 1$ was confirmed by real-time RT-PCR. We compared the ALDH1 expression in sphere forming cells and its parent cells. ALDH1 were highly expressed in spheroid-forming cells (SCN1 [5.71-fold], SCN2 [5.02-fold], SCN3 [7.52-fold], SCN4 [1.82-fold], and SCN5 [9.89-fold]) compared to their parent cells (Fig 1B). These results confirm that ALDH1-positivity is a marker of enriching cancer stem cells in OSC.

\section{Expression of Notch signaling genes in ALDH 1 $(+)$ cells in OSCs}

To determine the association between ALDH1 and Notch signaling, we compared the expression of
Notch signaling genes between FACS-sorted ALDH1 (+) OC cells and ALDH1 (-) OC cells using real-time RT-PCR. We have previously reported that ALDH1 $(+)$ cells increased Notch3 expression in OC cells [14]. In the present study, we confirmed expression Notch3 in ALDH (+) cells and verified the reproducibility of the data. In addition, we observed expression various Notch signaling genes in ALDH1 (+) cells. Notch3 was the most overexpressed gene in ALDH1 $\left(^{+}\right)$cells compared with ALDH1 $(-)$ cells (1.8-fold, $\mathrm{p}=0.046)$ (Fig.1C). Notch1 (1.2-fold, $\mathrm{p}=0.007)$, Jagged 2 (1.2-fold, $\mathrm{p}=0.101)$, and Hes1 (1.2-fold, $\mathrm{p}=0.033)$ were also overexpressed in ALDH1 (+) cells (Fig 1C). The expression of Notch2 and Jagged1 was not elevated in ALDH1 (+) cells.

\section{Expression of $A L D H I$ in ovarian epithelial tumors}

We evaluated the expression of ALDH1 and Notch 3 in OC, and compared the expression of these genes among various types of OC using real-time RT-PCR. Increased expression of ALDH1 (2.6-fold, $\mathrm{p}=$ $0.024)$ and Notch3 (13.7-fold, $\mathrm{p}=0.000)$ were observed in OC cells compared to normal control OE cells (Fig 2A). Furthermore, ALDH1 expression in mucinous (3.8-fold, $\mathrm{p}=0.014$ ) and endometrioid (2.5-fold, $\mathrm{p}=$ $0.029)$ carcinomas relative to $\mathrm{OE}$ cells was significantly elevated. Serous (2.6-fold, $p=0.24)$ and clear cell carcinomas (1.94-fold, $\mathrm{p}=0.315)$ also showed higher ALDH1 expression, although these results were not statistically significant (Fig.2B). These results indicate that high levels of ALDH1 and Notch3 related to development of OC.

\section{Expression of ALDH 1 and Notch signaling genes in chemoresistant OSC}

To determine the association of ALDH1 and Notch signaling genes with chemoresistance in OCs, we compared the expression levels of these genes between chemosensitive and chemoresistant OSC, the most common histologic type of OCs. Because OSCs compromise 80 percent among epithelial ovarian cancers and account for the majority of deaths from OC, we chose the serous carcinoma in this study. As for Notch3 among Notch signaling genes, we have previously demonstrated that increased expression of Notch3 in chemoresistant OC [14]. Here, we comprehensively evaluated expression patterns of ALDH1 and various Notch signaling genes in chemoresistant and chemosensitive OSCs. Compared with the chemosensitive group, Notch1 (2.9-fold, $\mathrm{p}<$ 0.001), Notch3 (3.4-fold, p < 0.001), Jagged2 (2.6-fold, p $=0.014)$, and Hes1 (2.7-fold, $p=0.003$ ) as well as ALDH1 (2.8-fold, p $<0.001$ ) were significantly upregulated by more than 2-fold in the 
chemoresistant group (Fig. 2C). The expression of ALDH1 positively and significantly correlated with that of Notch3 ( $\mathrm{R}=0.429, \mathrm{p}=0.007$, Spearman's correlation test) (Fig. 2D). ALDH1 expression did not significantly correlate with the expression of any other notch signaling genes. For detection of co-localization of Notch3 and ALDH1, we performed dual immunohistochemical stains for ALDH1 and Notch 3 proteins with 10 chemoresistant ovarian cancer tissues which showed high expression of Notch 3 mRNA. We found that all cases were stained with Notch 3 protein and 6 cases $(60 \%)$ were also showed ALDH1- positivity in Notch3-positive cancer cells (Fig. 2E).

\section{A}

ALDH \%
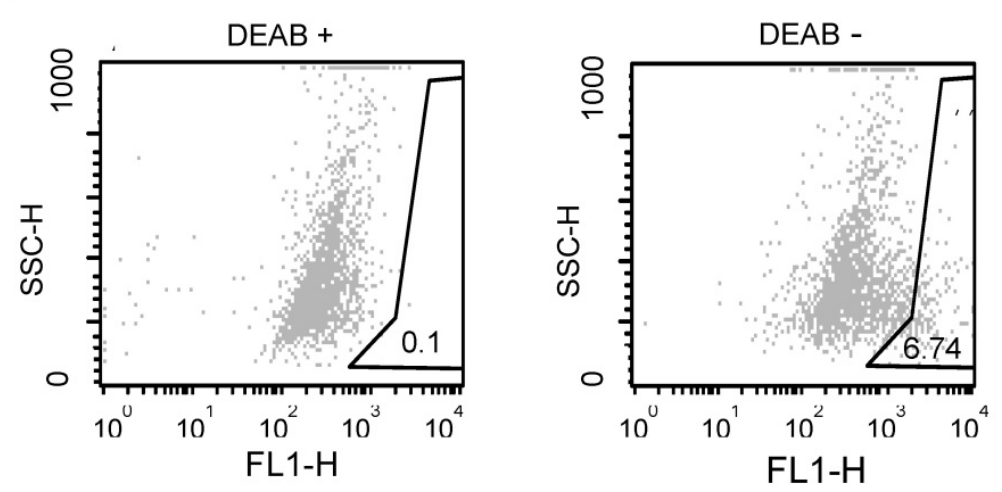

B

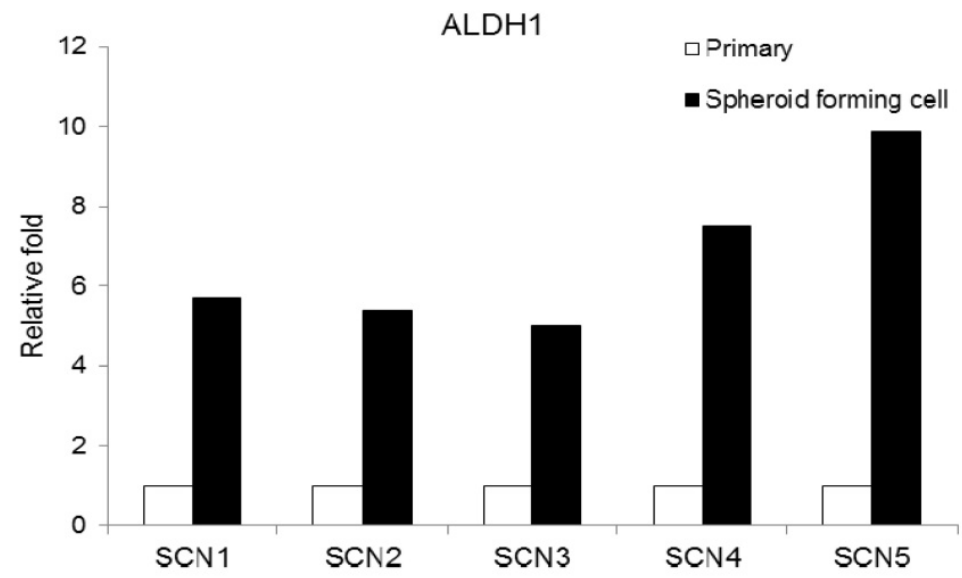

C

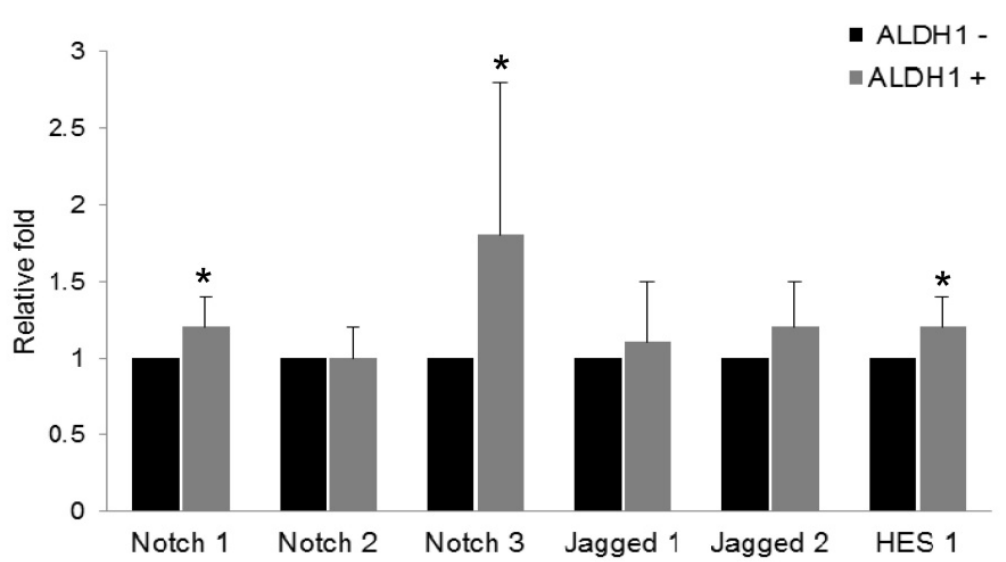

Figure 1. Aldefluor assay and the expression of ALDHI and Notch signaling genes in ovarian cancer stem cells. A. ALDHI population in primarily-cultured human ovarian carcinoma cells was analyzed by Aldefluor assay. DEAB is a specific inhibitor of ALDH and was used to confirm gating areas. ALDH 1 $(+)$ population $(6.74 \%$ ) was displayed in the absence of DEAB. B. Expression of ALDHI mRNA in parental carcinoma cells and spheroid forming cells from 5 primarily-cultured ovarian carcinoma cells (SCN 1-5). C. The mRNA expression of Notch signaling genes in FACS-sorted ALDHI (+) ovarian cancer cells. Notch3 $(1.8$-fold, $p=0.046)$, Notch I $(1.2$-fold, $p=0.007)$, and Hesl $(1.2$-fold, $p=0.033)$ were significantly overexpressed in ALDHI $(+)$ cells compared with ALDHI $(-)$ cells. 
A

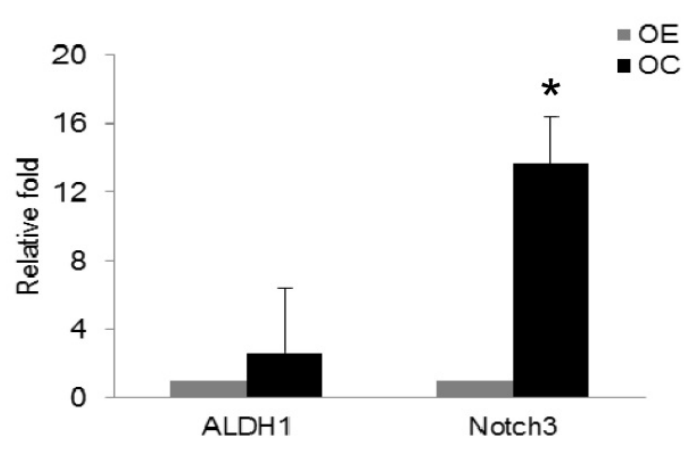

C

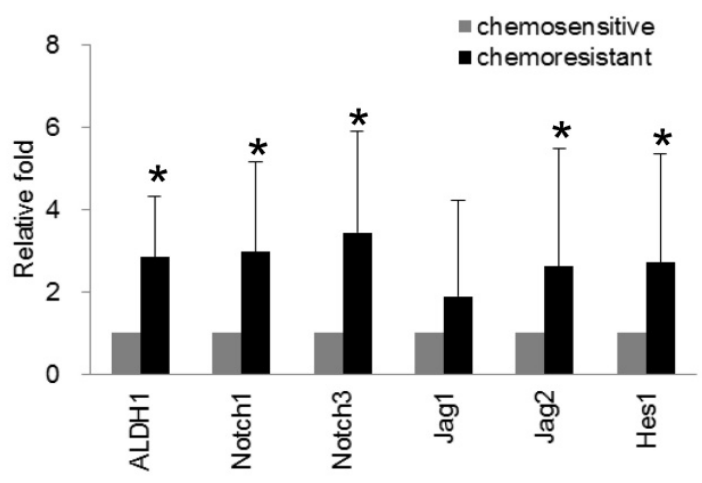

E

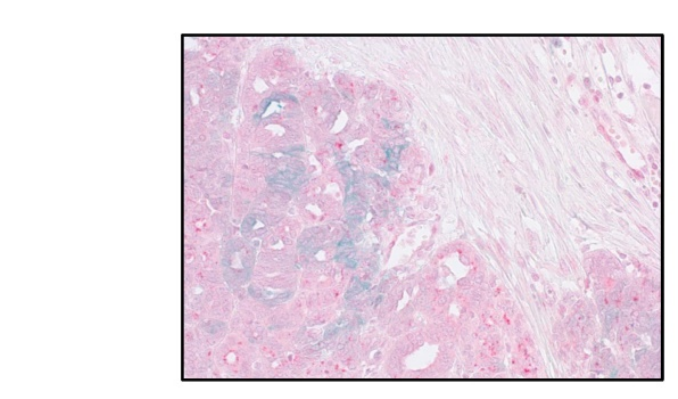

G

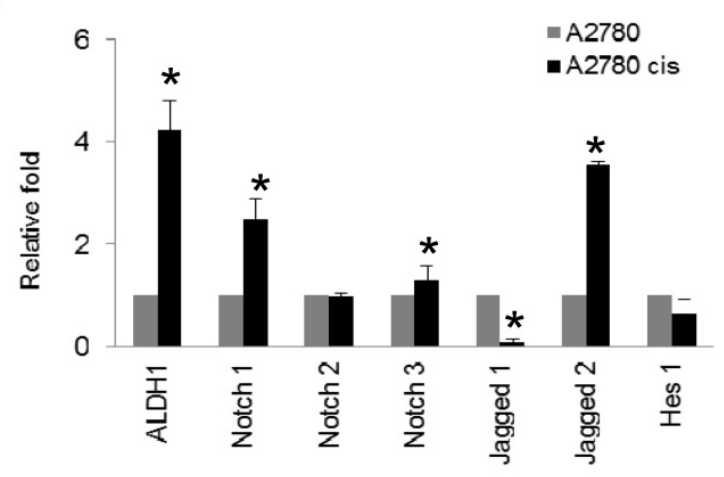

B
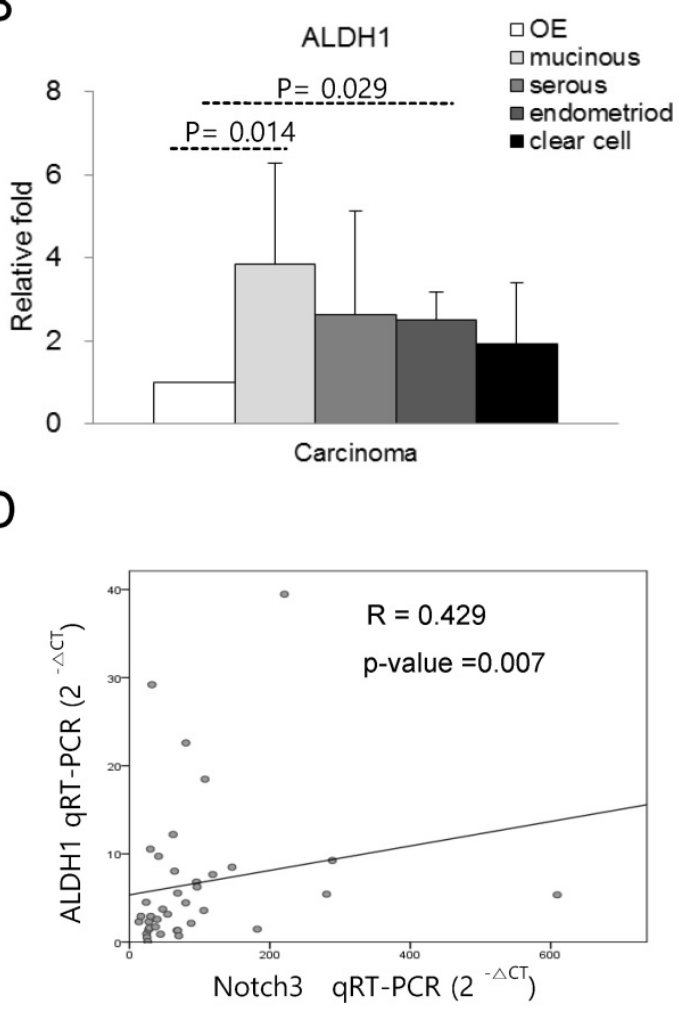

F

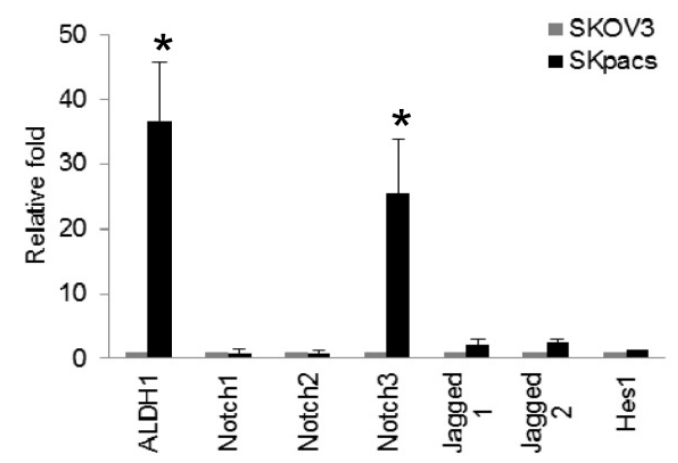

Figure 2. The mRNA expression of $A L D H I$ and Notch signaling genes in various subtypes of ovarian carcinomas and ovarian cancer cell lines. A. The mRNA expression of $A L D H I$ ( 2.6 -fold, $p=0.024)$ and Notch3 $(13.7$-fold, $p=0.000)$ was significantly upregulated in ovarian carcinomas $(O C)$ compared with normal epithelium $(O E)$. Each experiment was done in triplicate $(* p<0.05)$. B. The mRNA expression of $A L D H I$ was significantly elevated in mucinous $(3.8$-fold, $p=0.014)$ and endometrioid $(2.5$-fold, $p=$ $0.029)$ types of OC compared with OE. Serous carcinoma $(2.6$-fold, $p=0.24)$ also showed higher $A L D H I$ expression. Each experiment was done in triplicate $(* p<0.05)$. $\mathbf{C}$. The mRNA expression of Notchl (3.0-fold, $p<0.001)$, Notch3 (3.4-fold, $p<0.001)$, Jagged2 (2.6-fold, $p=0.014)$, Hesl (2.7-fold, $p=0.003)$, and ALDHI $(2.8$-fold, $p<0.001)$ was significantly upregulated in the chemoresistant group compared with the chemosensitive group of OSCs. D. The correlation between ALDHI and Notch 3 expression. Notch 3 expression was positively correlated with $A L D H I$ expression $(R=0.429, p=0.007$, Spearman's correlation test). E. Dual immunohistochemical stain for ALDHI and Notch 3 proteins in chemoresistant OSCs. The carcinoma cells showing diffuse cytoplasmic and nuclear staining with Notch 3 (red) were also stained with ALDH1 in the cytoplasm (blue-green). F. The mRNA expression of ALDHI and Notch signaling genes in PTX-resistant SKpac cells and PTX-sensitive parent SKOV3 cells. ALDHI and Notch 3 mRNA levels ( $>25$-fold than parent cells) were significantly elevated in SKpac cells compared with SKOV3 cells. Each experiment was done in triplicate (* $p<0.05)$. G. The expression of $\mathrm{ALDHI}$ and Notch signaling genes in cisplatin-resistant A2780cis cells and cisplatin-sensitive A2780 cells. ALDHI (4.2-fold, $\mathrm{p}=0.016)$, Notchl (2.5-fold, $\mathrm{p}=0.034), \mathrm{Notch} 3$ $(1.3$-fold, $\mathrm{p}=0.312)$, and Jagged2 $(3.6$-fold, $\mathrm{p}=0.001)$ mRNA levels were elevated in A2780cis cells compared with A2780. Each experiment was done in triplicate. $(* \mathrm{p}<0.05)$ 
To assess whether the expression of ALDH1 and Notch signaling genes is associated with chemoresistance, we also examined the expression of ALDH1 and Notch signaling genes in chemoresistant ovarian cancer cell lines. Compared with their parent chemosensitive cell lines, ALDH1 was overexpressed in PTX-resistant SKpac cells and cisplatin-resistant A2780cis cells by 36.7- and 4.2-fold, respectively (Fig. $2 \mathrm{~F}$ and G). Relative to SKOV3 cells, Notch 3 was the most overexpressed (25.5-fold, $\mathrm{p}<0.001)$ among the Notch signaling genes in SKpac cells, consistent with our previous results [14]. Relative to parent A2780 cells, Notch1 (2.5-fold, $\mathrm{p}=0.034)$, Notch3 (1.3-fold, $\mathrm{p}=$ 0.312), and Jagged 2 (3.6-fold, $p=0.001$ ), were significantly overexpressed in A2780cis cells.

\section{Correlation of Notch signaling genes with clinicopathological parameters in OSC}

To assess the clinical implication of Notch signaling genes and ALDH1 expression in OSC, we examined associations between mRNA expression of these genes and clinicopathological parameters, including the clinical stage, lymph node metastasis, distant metastasis, and the chemoresponsiveness (Table 2). An advanced clinical stage was significantly associated with high ( $\geq 2.0$-fold) Notch3 and Hes1 expression, while lymph node metastasis was significantly associated with Notch1 and Notch3 expression, and a high level of ALDH1, Notch3, and Hes1 was significantly associated with distant metastasis and chemoresistance. Interestingly, high Notch 3 expression was significantly associated with all of the poor prognostic parameters, namely advanced clinical stage $(p=0.008)$, lymph node metastasis $(p=0.010)$, distant metastasis $(p=0.026)$, and chemoresistance $(p=0.031)$.

\section{Survival analysis for expression of ALDHI and Notch signaling genes in OSC}

Follow-up data was available for all 38 patients with OSC, with the mean follow-up times of 28.4 months (range: 1.6 - 80.5 months). During this time-period, 13 patients (34.2\%) experienced tumor recurrence or persistence within 6 months after treatment, which represented resistance to a first-line chemotherapeutic regimen with PTX and carboplatin, while 8 patients $(21.0 \%)$ died of disease. The patients were divided into a high-expressing group and a low-expressing group for each tested gene based on real-time RT-PCR results and a cut-off value of 2-fold over the level in $\mathrm{OE}$ cells. A statistically significant difference in the overall survival (OS) was noted between the high-expressing and low-expressing group for ALDH1 (OS $58.3 \%$ vs. $88.5 \%, \mathrm{p}=0.019$ ), Notch1 (OS 53.8\% vs. 92\%, p = 0.016), Notch3 (OS $66.7 \%$ vs. $94.1 \%$, p < 0.001$)$, Jagged $1(70.4 \%$ vs. $100 \%$, p $=0.025)$, and Jagged 2 (OS $71.4 \%$ vs. $100 \%, p=0.024$ ) (Fig. 3). Hes1 expression was not associated with patient survival. A multivariate Cox regression analysis including $A L D H 1$ and Notch signaling gene expression, FIGO stage, lymph node metastasis, distant metastasis, and chemoresistance data revealed that a high expression of ALDH1 was the only independent predictor of a reduced OS (HR, 20.8; $95 \%$ CI, 1.05-412.38; $\mathrm{p}=$ 0.046; Table 3).

Table 2. Clinicopathological correlation of Notch signaling genes and ALDHI

\begin{tabular}{|c|c|c|c|c|c|c|c|c|c|c|c|c|}
\hline & \multicolumn{3}{|l|}{ Stage } & \multicolumn{3}{|l|}{ LN } & \multicolumn{3}{|c|}{ Metastasis } & \multicolumn{3}{|c|}{ Chemoresponse } \\
\hline & III,IV & I.II & $\mathrm{p}$-value & $\mathrm{P}$ & $\mathrm{N}$ & $\mathrm{p}$-value & $\mathrm{P}$ & $\mathrm{N}$ & p-value & $\mathrm{R}$ & $\mathrm{S}$ & p-value \\
\hline \multicolumn{13}{|c|}{ ALDH1 } \\
\hline$\geq 2.0$ & 13(39.4) & $0(0.0)$ & 0.084 & $5(50.0)$ & $8(28.6)$ & 0.220 & $11(52.4)$ & $2(11.8)$ & $0.009^{*}$ & $8(61.5)$ & $5(20.0)$ & $0.010^{*}$ \\
\hline$<2.0$ & $20(60.6)$ & $5(100)$ & & $5(50.0)$ & $20(71.4)$ & & $10(47.6)$ & 15(88.2) & & $5(38.5)$ & $20(80.0)$ & \\
\hline \multicolumn{13}{|c|}{ Notch1 } \\
\hline$\geq 2.0$ & $12(36.4)$ & $1(20.0)$ & 0.472 & $6(60.0)$ & $7(25.0)$ & $0.045^{*}$ & $8(38.1)$ & $5(29.4)$ & 0.575 & $7(53.8)$ & $6(24.0)$ & 0.066 \\
\hline$<2.0$ & $21(63.6)$ & $4(80.0)$ & & $4(40.0)$ & $21(75.0)$ & & $13(61.9)$ & 12(70.6) & & $6(46.2)$ & $19(76.0)$ & \\
\hline \multicolumn{13}{|c|}{ Notch3 } \\
\hline$\geq 2.0$ & $21(63.6)$ & $0(0.0)$ & $0.008^{*}$ & $9(90.0)$ & $12(42.9)$ & $0.010^{*}$ & 15(71.4) & $6(35.3)$ & $0.026^{*}$ & $10(76.9)$ & $10(40.0)$ & $0.031^{*}$ \\
\hline$<2.0$ & $12(36.4)$ & $5(100)$ & & $1(10.0)$ & $16(57.1)$ & & $6(28.6)$ & $11(64.7)$ & & $3(23.1)$ & $15(60.0)$ & \\
\hline \multicolumn{13}{|l|}{ Jag1 } \\
\hline$\geq 2.0$ & $25(75.8)$ & $2(40.0)$ & 0.100 & $9(90.0)$ & $18(64.3)$ & 0.124 & $17(81.0)$ & $10(58.8)$ & 0.135 & $10(76.9)$ & $16(64.0)$ & 0.416 \\
\hline$<2.0$ & $8(24.2)$ & $3(60.0)$ & & $1(10.0)$ & 10(35.7) & & $4(19.0)$ & $7(41.2)$ & & $3(23.1)$ & $9(36.0)$ & \\
\hline \multicolumn{13}{|l|}{ Jag2 } \\
\hline$\geq 2.0$ & $24(72.7)$ & $4(80.0)$ & 0.731 & $7(70.0)$ & $21(75.0)$ & 0.758 & $15(71.4)$ & $13(76.5)$ & 0.726 & $11(84.6)$ & $16(64.0)$ & 0.184 \\
\hline$<2.0$ & $9(27.3)$ & $1(20.0)$ & & $3(30.0)$ & $7(25.0)$ & & $6(28.6)$ & $4(23.5)$ & & $2(15.4)$ & $9(36.0)$ & \\
\hline \multicolumn{13}{|l|}{ Hes1 } \\
\hline$\geq 2.0$ & $28(84.8)$ & $1(20.0)$ & $0.008^{*}$ & $7(70.0)$ & $22(78.6)$ & 0.440 & 19(90.5) & $10(58.8)$ & $0.028^{*}$ & $12(92.3)$ & $15(60.0)$ & $0.037^{*}$ \\
\hline$<2.0$ & $5(15.2)$ & $4(80.0)$ & & $3(30.0)$ & $6(21.4)$ & & $2(9.5)$ & $7(41.2)$ & & $1(7.7)$ & $10(40.0)$ & \\
\hline
\end{tabular}

*, p<0.05, $\chi 2$-test

$\mathrm{P}$ : positive, N: Negative, R: resistant, S: Sensitive 
A.

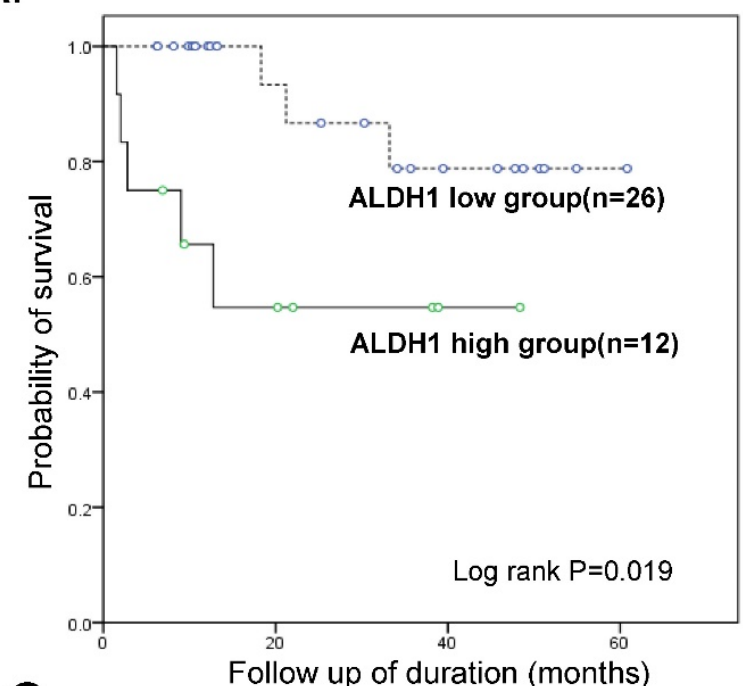

C.

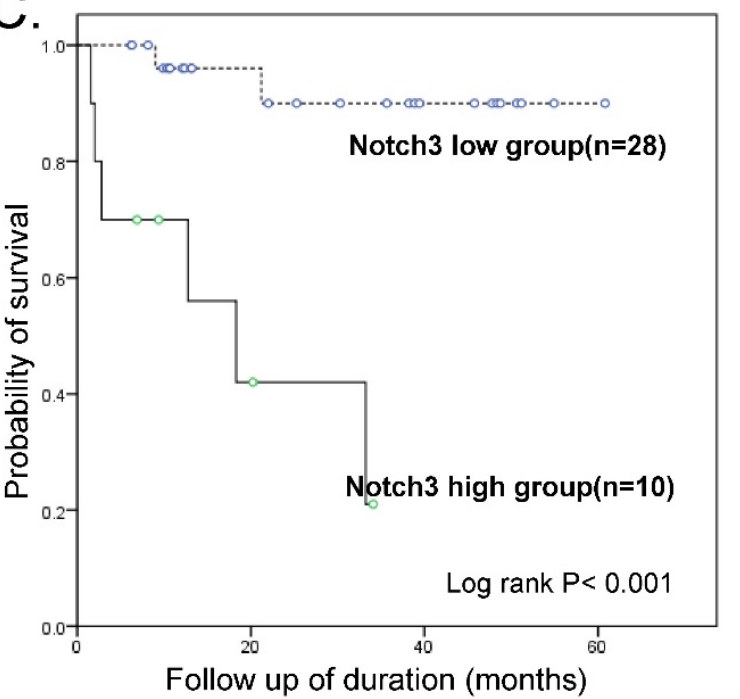

E.

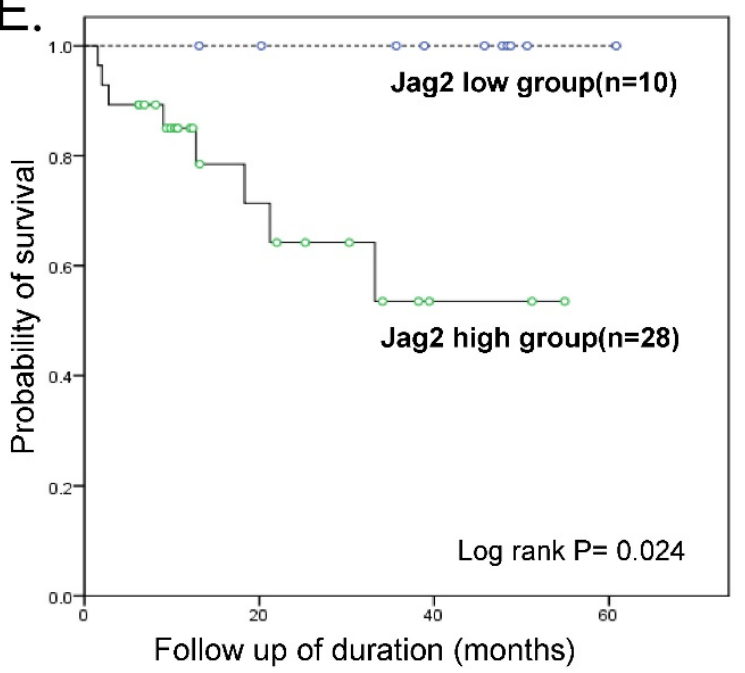

B.

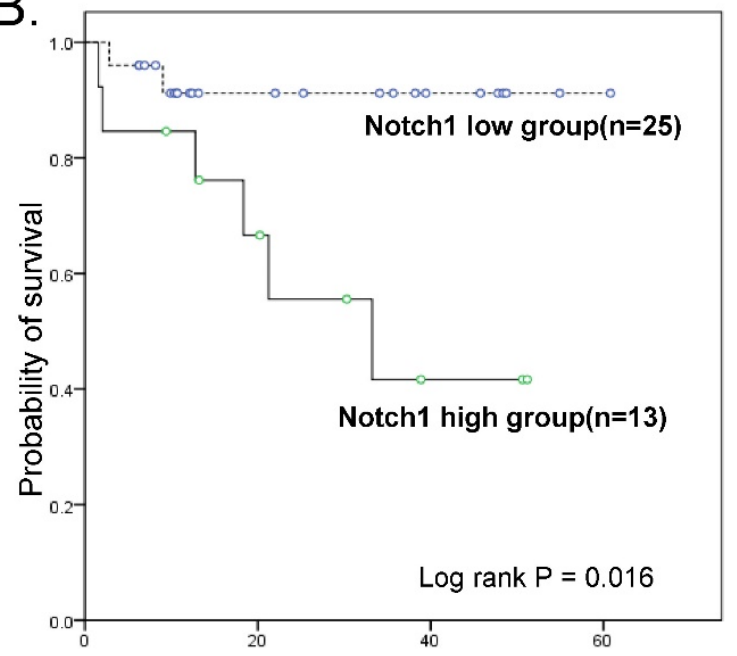

Follow up of duration (months)

D.

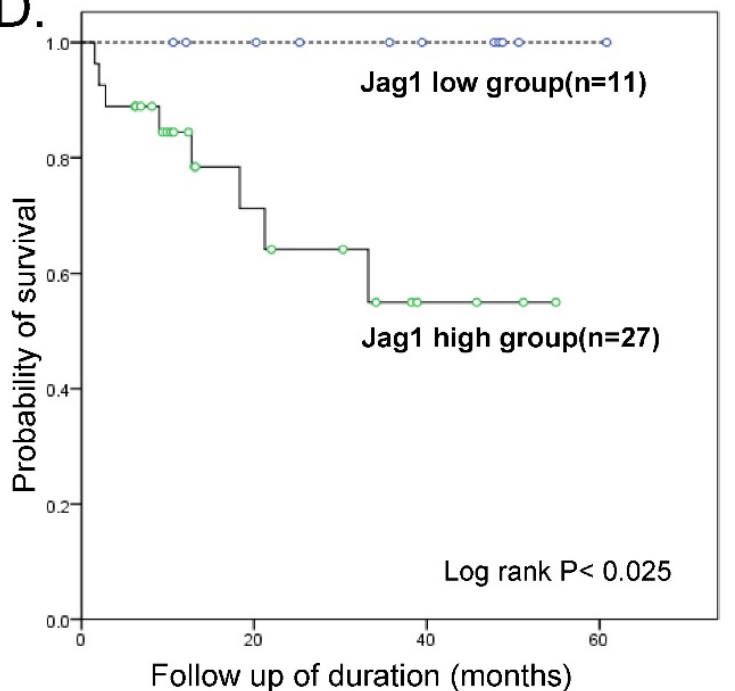

$\mathrm{F}$

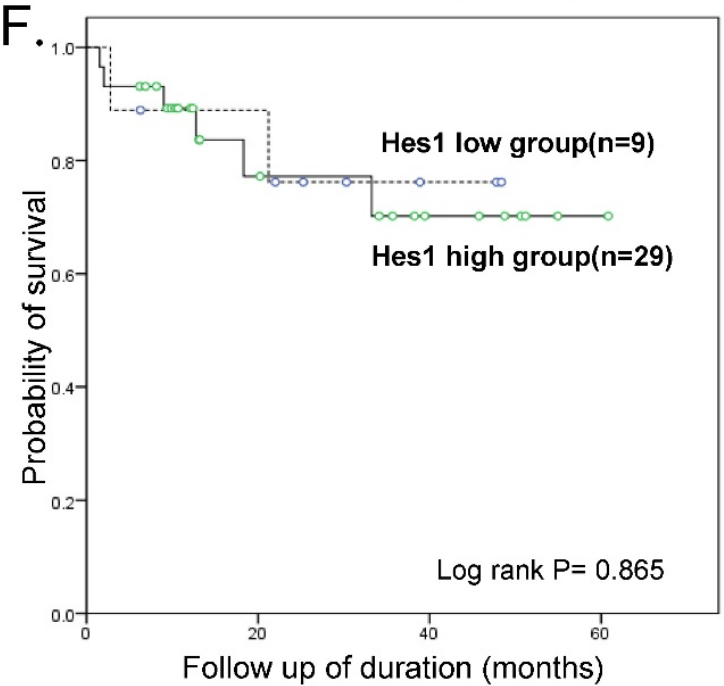

Figure 3. Kaplan-Meier overall survival curves. Within ovarian serous carcinomas, the groups that overexpressed ALDHI, Notch I, Notch3, Jagged I, and Jagged2 (but not Hesl) (>2-fold than normal epithelium) were significantly associated with a worse overall survival rate when compared with the groups that did not overexpress these genes. 


\section{Impact of combined ALDHI/Notch3 expression on patient survival}

Survival analyses were also performed with combined ALDH1 and Notch signaling gene expression data (Fig. 4). Kaplan-Meier analysis revealed a significant difference between patients with tumors that highly expressed ALDH1 and Notch signaling genes and those with tumors that did not. In particular, OS of patients with tumors that highly expressed both ALDH1 and Notch3 was exceptionally poor (OS 33.3\% vs. 93.1\%, p < 0.001) (Table 3).

Table 3. Multivariate survival analysis (Cox regression) for the patients of ovarian serous carcinomas.

\begin{tabular}{|c|c|c|c|}
\hline & HR & $95 \% \mathrm{CI}$ & $P$ \\
\hline \multicolumn{4}{|l|}{ ALDH1 } \\
\hline $\begin{array}{l}\text { Negative } \\
\text { Positive }\end{array}$ & 20.82 & $1.05-412.39$ & $0.046^{*}$ \\
\hline \multicolumn{4}{|l|}{ Notch1 } \\
\hline $\begin{array}{l}\text { Negative } \\
\text { Positive }\end{array}$ & 3.20 & $0.22-46.78$ & 0.396 \\
\hline \multicolumn{4}{|l|}{ Notch3 } \\
\hline $\begin{array}{l}\text { Negative } \\
\text { Positive }\end{array}$ & 0.55 & $0.02-14.44$ & 0.719 \\
\hline \multicolumn{4}{|l|}{ Stage } \\
\hline \multicolumn{3}{|l|}{$\begin{array}{l}\text { III } \\
\text { IV }\end{array}$} & 0.054 \\
\hline \multicolumn{4}{|l|}{$\mathrm{LN}$} \\
\hline $\begin{array}{l}\text { Negative } \\
\text { Positive }\end{array}$ & 3.49 & $0.46-26.26$ & 0.225 \\
\hline \multicolumn{4}{|l|}{ Metastasis } \\
\hline $\begin{array}{l}\text { Negative } \\
\text { Positive }\end{array}$ & 0.61 & $0.17-22.19$ & 0.789 \\
\hline \multicolumn{4}{|c|}{ Chemoresponse } \\
\hline $\begin{array}{l}\text { Sensitive } \\
\text { Resistant }\end{array}$ & 19.01 & $0.89-406.69$ & 0.060 \\
\hline \multicolumn{4}{|c|}{ ALDH1/Notch1 } \\
\hline $\begin{array}{l}\text { Negative } \\
\text { Positive }\end{array}$ & 0.80 & $0.06-10.78$ & 0.866 \\
\hline \multicolumn{4}{|c|}{ ALDH1/Notch3 } \\
\hline $\begin{array}{l}\text { Negative } \\
\text { Positive }\end{array}$ & 32.49 & $1.19-888.44$ & $0.039^{*}$ \\
\hline \multicolumn{4}{|l|}{ Stage } \\
\hline $\begin{array}{l}\text { I/II } \\
\text { III } \\
\text { IV }\end{array}$ & 122.68 & $3.00-5026.86$ & $0.011^{*}$ \\
\hline \multicolumn{4}{|l|}{ LN } \\
\hline $\begin{array}{l}\text { Negative } \\
\text { Positive }\end{array}$ & 6.11 & $0.59-62.84$ & 0.128 \\
\hline $\begin{array}{l}\text { Metastasis } \\
\text { Negative } \\
\text { Positive }\end{array}$ & 0.104 & $0.00-2.84$ & 0.180 \\
\hline \multicolumn{4}{|c|}{ Chemoresponse } \\
\hline $\begin{array}{l}\text { Sensitive } \\
\text { Resistant }\end{array}$ & 25.36 & $2.18-295.32$ & $0.010^{*}$ \\
\hline
\end{tabular}

When the Cox regression test was performed including combined high-expressing groups of ALDH1/Notch 1 or ALDH1/Notch 3, FIGO stage, lymph node metastasis, distant metastasis, and chemoresistance, a combined high-expressing group of ALDH1/Notch3 (HR, 32.5; 95\% CI, 1.18-888.43; $\mathrm{p}=0.039)$, high stage $(\mathrm{HR}, 122.7 ; 95 \% \mathrm{CI}, 2.99-5026.85$; $\mathrm{p}=0.011)$, and chemoresistance (HR, 25.4; 95\% CI, 2.18-295.32; $\mathrm{p}=0.010$ ) were the independent predictors of reduced OS (Table 3 ).

\section{Discussion}

ALDH1 is currently suggested to be a marker for the identification and isolation of various types of normal stem cells and CSCs [15], based on initial findings in hematopoietic stem cells [16], and then subsequent findings in neural [17] and adipose-derived adult stem cells [18]. Recently, the activity of cytosolic ALDH1 was proposed to be a reliable marker for CSCs in various solid tumors [19], including those of OC [6]. In this study, we also confirm that ALDH1 is a marker for CSCs, as demonstrating that spheroid forming cells showed significant overexpression of ALDH1 compared with their corresponding primary ovarian cancer cells. Furthermore, high level of ALDH1 is considered to be associated with poor prognosis in cancer patients, including those with breast [20] and prostate cancers [21]. For OC, there have been conflicting reports in terms of the prognostic importance of ALDH1. While Chang et al [22] demonstrated that high expression of ALDH1 is associated with early-stage disease, a complete response to chemotherapy, and longer OS, other researchers $[6,9]$ showed that ovarian cancer patients with high ALDH1 expression had a poor prognosis compared with those that did not. A result of these controversies may be due to different histologic subtypes. The OC comprises several subtypes, namely the serous, mucinous, endometrioid, and clear cell carcinomas. Chang et al [22] included different histologic subtypes in their study, whereas the other researchers focused on OSCs only. Moreover, most of these studies used immunohistochemistry (IHC) and the cut off value defining high $A L D H 1$ expression (10\% vs. $50 \%)$ might affect their results. In addition, the researchers did not examine $A L D H 1$ expression in $\mathrm{OE}$ or in benign tumors as a control.

In this study, we employed real-time RT-PCR and compared $A L D H 1$ expression of $\mathrm{OC}$ to that of $\mathrm{OE}$, thereby providing relatively objective results, unlike those of the previous studies. The mucinous and endometrioid types among OC types expressed significantly higher ALDH1 compared with the serous and clear cell types. These results are in accordance with those of Wang et al. [8], who showed that high ALDH1 expression ( $>50 \%$ of tumor cells by IHC) was present in most mucinous and endometrioid type whereas low levels existed in the clear cell type and heterogeneous expression was found in the serous type. The high expression of ALDH1 in mucinous OC, 
that suggest a high proportion of CSCs, may be related to a poor response to chemotherapy and a

A.

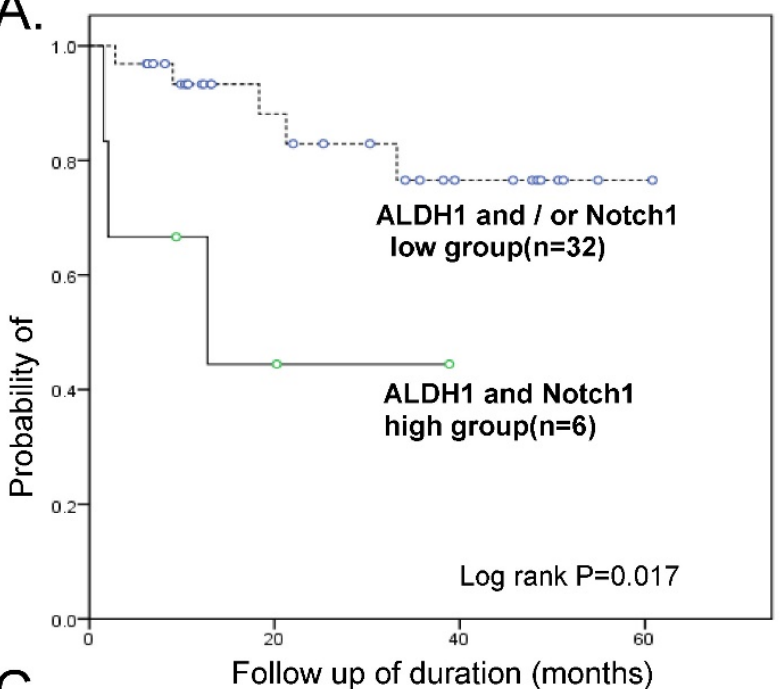

C.

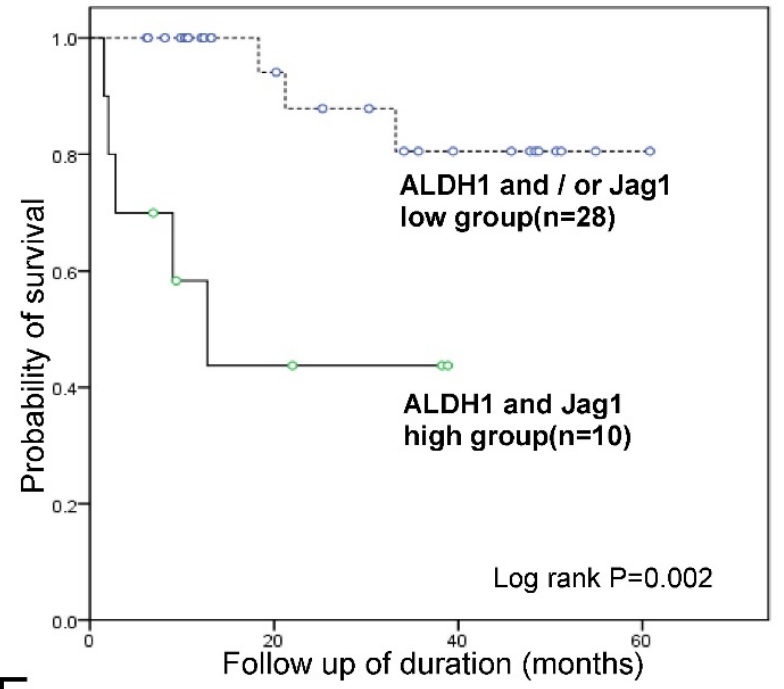

E.

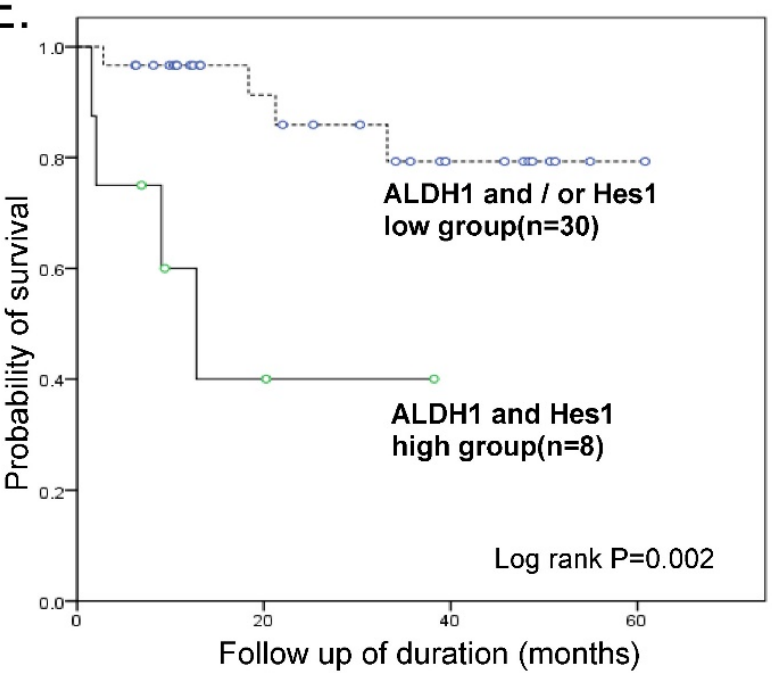

worse prognosis in patients with mucinous OC [23, 24].

B.
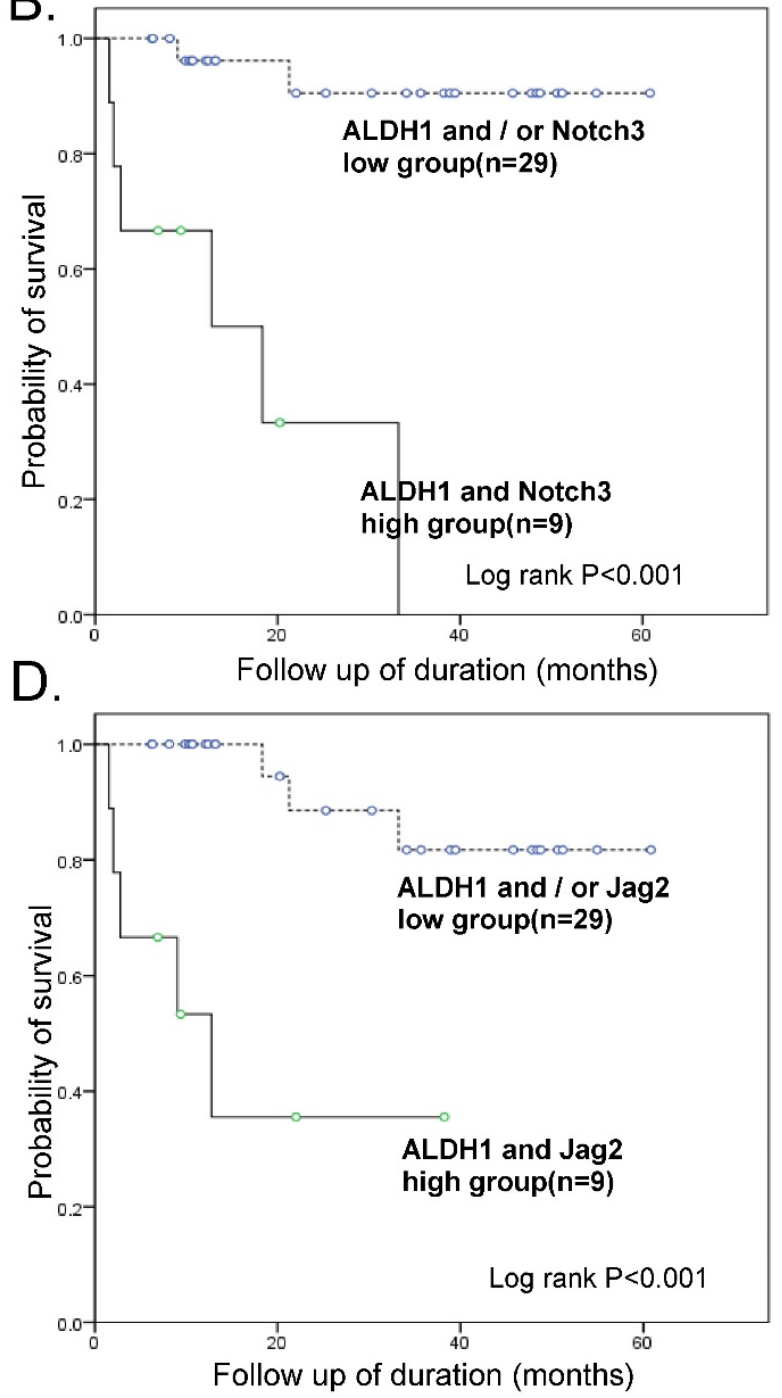

Figure 4. Kaplan-Meier overall survival curve of groups of combined overexpressing ALDHI and notch signaling genes. The groups overexpressing ALDHI and Notch 3 had exceptionally poor prognosis (OS $33.3 \%$ vs. $93.1 \%, p<0.001$ ) 
In this study, we paid special attention to the relationship between $A L D H 1$ and Notch signaling genes for OSC. We found that, compared with ALDH1 (-) cells, ALDH1 (+) OC cells significantly overexpressed Notch signaling genes to a higher degree, of which Notch3 was the most overexpressed, and there was a positive correlation between ALDH1 and Notch3 mRNA expression. The correlation between ALDH1 and Notch3 was previously reported in two in vitro studies. Xiao et al[25] reported dual immunoreactivities of ALDH1 and Notch3 intracellular domain in spheroids from inflammatory breast cancer cells. Another study by Zhang et al[26] demonstrated that Notch3-positive cells had higher levels of ALDH activity in hepatoma cell line. The results of both studies were obtained from in vitro analyses, however, we found the positive correlation between Notch3 and ALDH1 expression in human ovarian cancer tissues, which is the first report for the correlation of these two mRNA expressions using ex vivo human samples. Although the overexpression of $A L D H 1$ was reportedly related to the development or prognosis of various human cancers in several studies, and Notch 3 among the Notch signaling genes that are part of a key ovarian CSC pathway was also revealed to be responsible for recurrence and resistance to platinum therapy in OSCs in several previous studies $[13,27]$ including ours [11], there have been no comprehensive and comparative expression analyses that emphasized their clinical implication in OSC. As for other cancers, two previous studies examined the immunohistochemical profiles of several CSC markers including ALDH1 and Notch3, in colorectal micropapillary carcinomas [28] and pancreatic ductal adenocarcinomas [29], however they did not analyze the relationship between these two proteins or clinical implication of expression of these proteins. In this study, we found that a combined upregulation of ALDH1 and Notch3 is an independent poor prognostic factor in ovarian carcinomas, which is a totally novel finding.

We also found significantly higher expression levels of ALDH1 and Notch related genes in chemoresistant OSCs, when they were divided into chemosensitive and chemoresistant groups for OSC tumors and cell lines. This finding suggests that a higher proportion of CSCs results in the development of chemoresistance, and also supports recent reports demonstrating an association between $A L D H 1$ and chemoresistance in OSC $[6,8]$.

In the present study, we determined the clinical significance of the expression of the Notch signaling genes Notch1, Notch3, Jagged1, Jagged2, and Hes1 as well as ALDH1 in OSC. While high Notch3 expression was significantly associated with all the parameters of poor prognosis, i.e., an advanced stage, the presence of lymph node and distant metastases, and chemoresistance, other tested genes were less correlated with these parameters. Furthermore, multivariate Cox analysis and a Kaplan-Meier survival curve revealed that the combined upregulation of ALDH1 and Notch3 along with an advanced clinical stage and chemoresistance was the strongest independent unfavorable prognostic indicator for patient's overall survival. The combined overexpression of ALDH1 and Notch3 strengthened the predictable power for worse overall survival, compared with that of $A L D H 1$ overexpression only.

In summary, we found that ALDH1 is differentially expressed in different subtypes of OC, demonstrating specifically that higher ALDH1 expression exists in mucinous, endometriod, and chemoresistant serous carcinoma. Furthermore, we showed that ALDH1 expression positively correlates with Notch3 expression, and that the combined upregulation of these genes is an independent poor prognostic indicator in OSC.

\section{Acknowledgements}

This work was supported by grants from the Korean Government, NRF 2015-R1A2A2A01005197.

\section{Competing Interests}

The authors have declared that no competing interest exists.

\section{References}

1. Siegel R, Naishadham D, Jemal A. Cancer statistics, 2012. CA: a cancer journal for clinicians. 2012; 62: 10-29.

2. Cannistra SA. Cancer of the ovary. The New England journal of medicine. 2004; 351: 2519-29.

3. Clarke MF, Fuller M. Stem cells and cancer: two faces of eve. Cell. 2006; 124: 1111-5.

4. Reya T, Morrison SJ, Clarke MF, Weissman IL. Stem cells, cancer, and cancer stem cells. Nature. 2001; 414: 105-11.

5. Silva IA, Bai S, McLean K, Yang K, Griffith K, Thomas D, et al. Aldehyde dehydrogenase in combination with CD133 defines angiogenic ovarian cancer stem cells that portend poor patient survival. Cancer research. 2011; 71: 3991-4001.

6. Deng S, Yang X, Lassus H, Liang S, Kaur S, Ye Q, et al. Distinct expression levels and patterns of stem cell marker, aldehyde dehydrogenase isoform 1 (ALDH1), in human epithelial cancers. PloS one. 2010; 5: e10277.

7. Ma I, Allan AL. The role of human aldehyde dehydrogenase in normal and cancer stem cells. Stem cell reviews. 2011; 7: 292-306.

8. Wang YC, Yo YT, Lee HY, Liao YP, Chao TK, Su PH, et al. ALDH1-bright epithelial ovarian cancer cells are associated with CD44 expression, drug resistance, and poor clinical outcome. The American journal of pathology. 2012; 180: 1159-69.

9. Landen CN, Jr., Goodman B, Katre AA, Steg AD, Nick AM, Stone RL, et al. Targeting aldehyde dehydrogenase cancer stem cells in ovarian cancer. Molecular cancer therapeutics. 2010; 9: 3186-99.

10. Park YT, Jeong JY, Lee MJ, Kim KI, Kim TH, Kwon YD, et al. MicroRNAs overexpressed in ovarian ALDH1-positive cells are associated with chemoresistance. Journal of ovarian research. 2013; 6: 18.

11. Jung SG, Kwon YD, Song JA, Back MJ, Lee SY, Lee C, et al. Prognostic significance of Notch 3 gene expression in ovarian serous carcinoma. Cancer science. 2010; 101: 1977-83.

12. Park JT, Li M, Nakayama K, Mao TL, Davidson B, Zhang Z, et al. Notch3 gene amplification in ovarian cancer. Cancer research. 2006; 66: 6312-8.

13. Park JT, Chen X, Trope CG, Davidson B, Shih Ie M, Wang TL. Notch3 overexpression is related to the recurrence of ovarian cancer and confers 
resistance to carboplatin. The American journal of pathology. 2010; 177: 1087-94.

14. Kang H, Jeong JY, Song JY, Kim TH, Kim G, Huh JH, et al. Notch3-specific inhibition using siRNA knockdown or GSI sensitizes paclitaxel-resistant ovarian cancer cells. Molecular carcinogenesis. 2016; 55: 1196-209.

15. Douville J, Beaulieu R, Balicki D. ALDH1 as a functional marker of cancer stem and progenitor cells. Stem cells and development. 2009; 18: 17-25.

16. Vasiliou V, Nebert DW. Analysis and update of the human aldehyde dehydrogenase (ALDH) gene family. Human genomics. 2005; 2: 138-43.

17. Corti S, Locatelli F, Papadimitriou D, Donadoni C, Salani S, Del Bo R, et al. Identification of a primitive brain-derived neural stem cell population based on aldehyde dehydrogenase activity. Stem Cells. 2006; 24: 975-85.

18. Estes BT, $\mathrm{Wu} \mathrm{AW}$, Storms RW, Guilak F. Extended passaging, but not aldehyde dehydrogenase activity, increases the chondrogenic potential of human adipose-derived adult stem cells. Journal of cellular physiology. 2006; 209: 987-95.

19. Visvader JE, Lindeman GJ. Cancer stem cells in solid tumours: accumulating evidence and unresolved questions. Nature reviews Cancer. 2008; 8: 755-68.

20. Ginestier C, Hur MH, Charafe-Jauffret E, Monville F, Dutcher J, Brown M, et al. ALDH1 is a marker of normal and malignant human mammary stem cells and a predictor of poor clinical outcome. Cell stem cell. 2007; 1: 555-67.

21. van den Hoogen C, van der Horst G, Cheung H, Buijs JT, Lippitt JM, Guzman-Ramirez N, et al. High aldehyde dehydrogenase activity identifies tumor-initiating and metastasis-initiating cells in human prostate cancer. Cancer research. 2010; 70: 5163-73.

22. Chang B, Liu G, Xue F, Rosen DG, Xiao L, Wang X, et al. ALDH1 expression correlates with favorable prognosis in ovarian cancers. Modern pathology : an official journal of the United States and Canadian Academy of Pathology, Inc. 2009; 22: 817-23.

23. Hess V, A'Hern R, Nasiri N, King DM, Blake PR, Barton DP, et al. Mucinous epithelial ovarian cancer: a separate entity requiring specific treatment. Journal of clinical oncology : official journal of the American Society of Clinical Oncology. 2004; 22: 1040-4.

24. Bamias A, Psaltopoulou T, Sotiropoulou M, Haidopoulos D, Lianos E, Bournakis E, et al. Mucinous but not clear cell histology is associated with inferior survival in patients with advanced stage ovarian carcinoma treated with platinum-paclitaxel chemotherapy. Cancer. 2010; 116: 1462-8.

25. Xiao Y, Ye Y, Zou X, Jones S, Yearsley K, Shetuni B, et al. The lymphovascular embolus of inflammatory breast cancer exhibits a Notch 3 addiction. Oncogene. 2011; 30: 287-300.

26. Zhang $\mathrm{O}$, Lu C, Fang T, Wang $\mathrm{Y}, \mathrm{Hu} \mathrm{W}$, Qiao J, et al. Notch3 functions as a regulator of cell self-renewal by interacting with the beta-catenin pathway in hepatocellular carcinoma. Oncotarget. 2015; 6: 3669-79.

27. McAuliffe SM, Morgan SL, Wyant GA, Tran LT, Muto KW, Chen YS, et al. Targeting Notch, a key pathway for ovarian cancer stem cells, sensitizes tumors to platinum therapy. Proceedings of the National Academy of Sciences of the United States of America. 2012; 109: E2939-48.

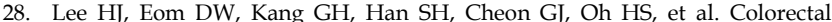
micropapillary carcinomas are associated with poor prognosis and enriched in markers of stem cells. Modern pathology : an official journal of the United States and Canadian Academy of Pathology, Inc. 2013; 26: 1123-31.

29. Vizio B, Mauri FA, Prati A, Trivedi P, Giacobino A, Novarino A, et al Comparative evaluation of cancer stem cell markers in normal pancreas and pancreatic ductal adenocarcinoma. Oncology reports. 2012; 27: 69-76. 